\title{
Ultra Capacitor as a Source for Smart Street Light
}

\author{
Er. Abhinav Dogra \\ Dept. of Electrical Engineering \\ Baddi University of Emerging Sciences and Technology, \\ Baddi, India
}

\begin{abstract}
Street Lights can be termed as unseen, unnoticed and most underrated electrical appliance. We do not feel their presence till the time it is working as it is supposed to. However it comes to everyone's notice when it does not work as it is supposed to. Ideal street light should be on when its dark outside and should be off when its bright. For carry out this functionality a person is appointed by the municipal corporation but there are always chances for human error. In order to overcome we have to remove the human factor from the process with the help of automation. Automation is implied for the decrease of labor as the human has gotten to be excessively occupied and even incapable, making it impossible to discover time to switch the lights. Presently a day's everybody are mindful of the availability of limited power sources like coal, biomass, and hydro and so on. Unnecessary wastage of power in the street lights is one of the noticeable power losses. To this making the lighting system independent of external source is a big leap in terms of smart lighting system. In this setup the street light won't require a supply and the street light will practically be independent. To achieve this I am using UltraCapacitors as a source of energy.
\end{abstract}

Index Terms- Renewable Energy, Smart street light, UltraCapacitor, Lux Sensor, Motion Sensor

\section{INTRODUCTION}

The idea of this kind of setup came in existence when I saw the issues occurring in my locality and then I noticed that the issue is just not in my locality but can be normally seen everywhere. As a citizen my duty is go get my surrounding safe and this was possible for me as I can use my technical knowledge and new technological inventions that will help me achieve the goal.

The image shown below is taken from a locality where it can be easily seen that some of the street lights are not working(can be seen circled) and it has been like this from past one year. On moving forward I found that these are not the only one that are not working but more than $50 \%$ of lights are not working.

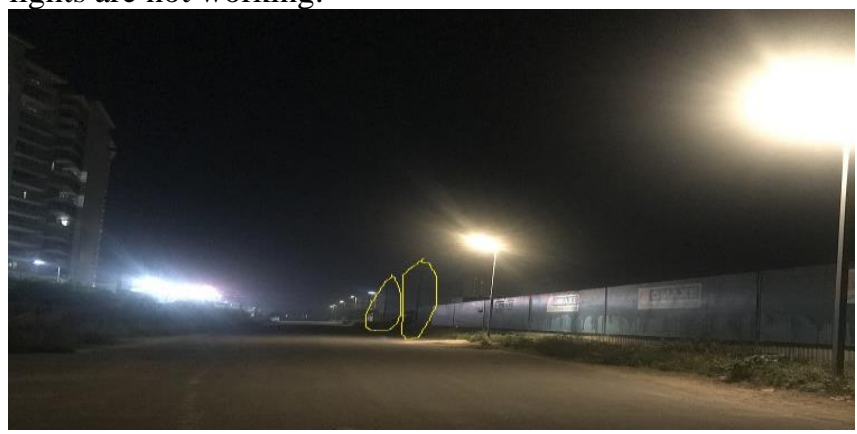

\author{
Er. Ashish Sharma \\ Dept. of Electrical Engineering \\ Baddi University of Emerging Sciences and Technology, \\ Baddi, India
}

The goal of this project is to develop a Battery Less Independent Smart Street Lighting System (BAISL) for anywhere use. In order to achieve this goal, a single control unit is needed for each lamp. In this way the system can individually control the street light depending on the brightness of the environment by means of light sensors, motion sensors and a smart control system. Experimental results are provided to show the effectiveness of the proposed solution.

With the wide accessibility of adaptable lighting innovation like light transmitting diode (LED) lights and all over accessible remote web association, quick responding, dependable working, and power moderating street lighting frameworks get to be reality. The reason for this work is to portray the BAISL framework, a first way to deal with perform the interest for adaptable smart lighting frameworks. The goal of this undertaking is to plan an automated lighting framework which focuses on the saving of power; to construct a vitally energy efficient smart lighting framework with integrated sensors and controllers; to outline a smart lighting framework with particular methodology plan, which makes the framework adaptability and expandability and configuration a smart lighting framework which similarity and versatility with other commercial products and mechanized automated system, which may incorporate more than lighting frameworks. And when we achieve this, all we need to do is make it independent.

BAISL has the potential to be deployed anywhere in any kind of terrain without second thoughts. These street lights can be installed even to the remotest area of our country or anywhere in the world without even thinking about the maintenance cost or process.

\section{PROBLEM OF CURRENT SETUP}

Current set up of Solar Light:- Solar street lights[12] are raised light sources which are powered by solar panels generally mounted on the lighting structure or integrated into the pole itself. The solar panels charge a rechargeable battery, which powers a fluorescent or LED lamp during the night. Most solar lights turn on and turn off automatically by sensing outdoor light using solar panel voltage. Solar streetlights are designed to work throughout the night. Many can stay lit for more than one night if the sun is not in the sky for an extended period of time. Older models included lamps that were not fluorescent or LED. [4] 
Batteries will store the electricity generated by the solar panel during the day and provide energy to the fixture during the night. The life cycle of the battery is very important to the lifetime of the light and the capacity of the battery will affect the backup days of the lights. There are two types of batteries commonly used in solar-powered street lights- gel cell deep cycle batteries as well as lead acid batteries. Lithium-ion batteries[1] are also popular these days as they are compact in size and not prone to theft[13] due to their lack of use in other situations unlike lead acid batteries.

Now the issues with battery are many that are electrical in nature and some non-electrical in nature.

1. Battery life

2. Numbers of charge cycle

3. Efficiency

4. Time to charge

5. Shelf life

6. Weather

7. Theft

8. Price

We can use UltraCapacitors[6] in place of batteries as there tested life cycle is about $10+$ years and because there is no chemical involved and charge stores as a electrical energy and output is also electrical energy hence the cycles can go up to millions of charge and discharge cycles.

As there is no energy conversion taking place hence the efficiency also goes up to $99 \%$ [15] and the charging time of capacitors are extremely shorter. Now the UltraCapacitors works on 2.7Volts-3.2 Volts this means in case of cloudy days as well the capacitor will charge to its full capacity.

The shelf life of UltraCapacitors are also very high and it does not deteriorate with time as there is no chemical used in it. Battery have a high risk of exploding if punctured however with UltraCapacitors this is not the case. They are extremely safe and reliable.[15]

Batteries and capacitors seem similar as they both store and release electrical energy. However, there are crucial differences between them that impact their potential applications due to how they function differently. [15]

Although UltraCapacitors also have some drawbacks like the power to weight ratio is very less as compared to battery but UltraCapacitors

\section{CIRCUIT DIAGRAM}

This is very simple and basic setup with very simple circuit diagram and as we will be working on DC hence the calculation will be simple as there is no part of reactive or apparent power components.[3]

\section{Charging Cycle}

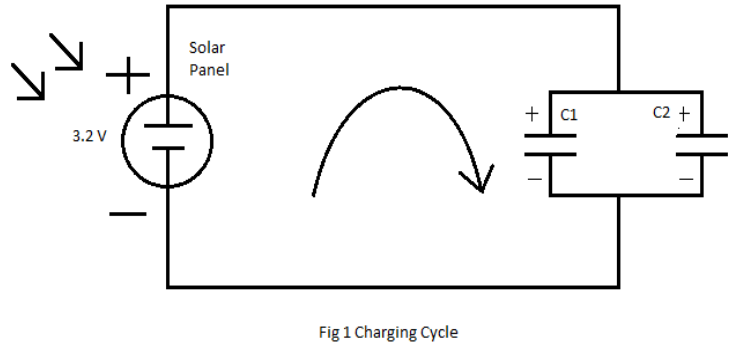

2. Discharging Cycle

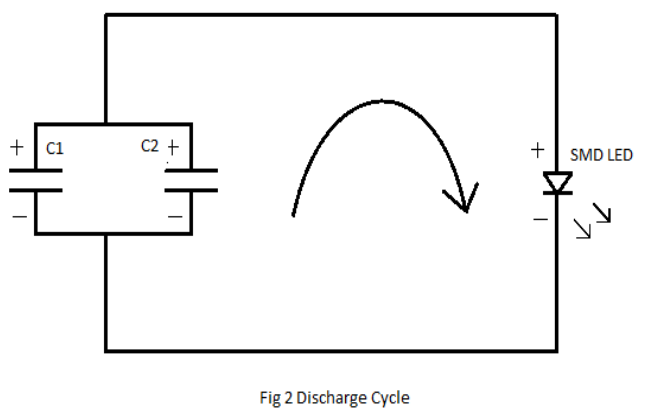

It seems a simple setup but making it work is a real challenge as the discharge of a capacitor is exponential and the voltage we are dealing here with makes it really complicated as the operating window is very narrow because as the voltage reaches below 2.75 volts[15] (approx.) the intensity of SMD LED falls. To overcome this situation we need to use a controller.

A controller[3],[6] is a major component as it does not only controls the discharge of UltraCapacitors but also controls the UltraCapacitors from over charging and Over voltage protection.[8]

The goal is to light up a SMD LED using UltraCapacitors as a source.

\section{Operating cost of current setup:-}

In a municipality we have approximately $150-200$ street lights.

For calculation purpose I will start with calculation operating cost of 1 street light.

On enquiring I found out that the street lights are equipped with 45W LED bulbs.

Connected Load $=45 \mathrm{~W}$

Operating time on an average $=7$ P.M. to 7 A.M. $=12$ Hours

Total Energy consumed $=45 \times 12$ $=540 \mathrm{Wh} / \mathrm{day}$ 


$$
\begin{aligned}
& =540 \times 365 \\
& =197100 \mathrm{Wh} / \text { year }=197.1 \mathrm{KWh} / \text { Year }
\end{aligned}
$$

Unit charges in Baddi (Himachal Pradesh) India is approx. Rs 6/KWh (INR)

$$
\begin{aligned}
& =197 \times 5 \\
& =\text { Rs 985/year }
\end{aligned}
$$

And if we operate around 200 street light per year

$$
\begin{aligned}
& =985 \times 200 \\
& =\operatorname{Rs} 1,97,000 \text { (approx.) INR }
\end{aligned}
$$

Here I have not included the maintenance charges or Installation charges. This is just the Ideal operational cost.

This may increase as many a time the street lights are running throughout the day and many of them don't work.

This is just assumption and not actual figures.

Actual Calculations:

$\mathrm{Q}=\mathrm{CV}$

$\mathrm{C}=$ Capacitance

$\mathrm{V}=$ Voltage

$\mathrm{Q}=$ Charge (In Columbs)

Energy Stored in UltraCapacitor:

$\mathrm{W}=1 / 2 \mathrm{QV}$

$\mathrm{W}=1 / 2 \mathrm{CV}^{2}$

Now when :

$\mathrm{V}=3 \mathrm{~V}$

$\mathrm{C}=100 \mathrm{~F}$

$\mathrm{Q}=100 \times 3=300$ Columbs

Energy Stored in 100 Farad Capacitor:

$\mathrm{W}=1 / 2 \times 300 \times 3$

$=450$ Joules

1 Joule $=1$ Watt per Second

450 Joules $=450$ Watts per Second

$\mathrm{P}=\mathrm{VI}$

$450=3 \times I$

$\mathrm{I}=150 \mathrm{~A}$
One 100F capacitor can give out 150 amps of current in one second. Internal resistance of this capacitor ideally is $0.02 \Omega$.

2. Cost of Battery Based street light setup:-

\begin{tabular}{|l|l|}
\hline Particular & Description \\
\hline Solar Light & 24 Watt \\
\hline Solar Panel & 100 Watt \\
\hline Solar Battery & $75 \mathrm{Ah}$ \\
\hline GI pole & 5 meters \\
\hline Charge Controller & Inbuilt \\
\hline Price & Rs. 21000 \\
\hline
\end{tabular}

The above mentioned charges are for a single street light setup with battery[4]. There is no operating cost in this setup however the maintenance charges are high as the battery used here does not have high life cycle and the charging and discharging cycles are also limited. Also there are always chances of battery theft. On other hand there is option to use Li-Ion batteries which will further increase the cost of this setup with the drawbacks of battery still in picture.

3. Cost of UltraCapacitors based Smart Street light[14] Setup: - The setup charges of UltraCapacitors based street light remains almost the same. We can use the same controller as being used in battery based setup with slight modification. The major change in this setup is instead of battery we will use UltraCapacitors which will help us overcome all the battery based issues and because we can store the UltraCapacitor bank within the GI pole cavity hence there will be no issue of theft.

\section{ULTRACAPACITORS}

I have been using the word UltraCapacitors[2],[10] a lot here as UltraCapacitor is the most important part of this project. Let me explain what a UltraCapacitor actually is. UltraCapacitor is very much like a common capacitor but with very high charge storing capacity. The normal capacitors where they can store charge of magnitude of $\mathrm{pF}$ or $\mathrm{nF}$ or $\mathrm{mF}$, the UltraCapacitors can store the charge of magnitude of around many Farads. The UltraCapacitors developed are of capacity of $1 \mathrm{~F}, 50 \mathrm{~F}, 100 \mathrm{~F}, 500 \mathrm{~F}, 1000 \mathrm{~F}$ and the UltraCapacitor I have seen is developed by Maxwell Technologies and is of 3000F. We can use combination of these to manipulate and get the required output.

Now how can UltraCapacitors can hold such a large amount of charge in a very small place. The answer is

1. The voltage is very less which saves space used for dielectric material.

2. The Material used in the UltraCapacitor is Graphene.

Graphene is a material with single layer of carbon atom which has high electric conductivity and high thermal conductivity.

An UltraCapacitor, also known as a supercapacitor, or electrochemical capacitor, is a device for storing electrical energy which is growing rapidly in popularity. The design 
and mechanism of operation is somewhere between an ordinary capacitor and a battery, which opens up some interesting and valuable applications.

Like a battery, a single UltraCapacitor cell consists of a positive and negative electrode, separated by an electrolyte. However, UltraCapacitors store energy electrostatically, like a regular capacitor, not chemically like a battery - there is a

dielectric separator dividing the electrolyte, also like a capacitor.

The small separation between electrodes permitted by this structure lead to much higher energy storage density than a normal capacitor. Whilst an UltraCapacitor stores less energy than an equivalently sized battery, it can release it much quicker, as the discharge is not dependent on a chemical reaction taking place.

Because no physical or chemical changes occur when charge is stored, UltraCapacitors can also be used many times over without degradation

UltraCapacitors using graphene electrodes show great promise, due to the remarkable electrical properties of the material. The technology is still in its infancy, however, and the degree of control over the electrode's structure which is needed is still difficult to achieve.

It is currently possible to make graphene UltraCapacitors with equivalent characteristics to more established materials, but at far greater cost. In the near future, however, graphene technology is likely to take over this market, as the potential performance benefits are huge.

1. For Discharging:

a. Capacitor discharge (voltage decay): $\mathrm{V}=\mathrm{Vo}^{*} \mathrm{e}-(\mathrm{t} / \mathrm{RC})$

b. Capacitor discharge (charge decay): $\mathrm{Q}=\mathrm{Qo} * \mathrm{e}-(\mathrm{t} / \mathrm{RC})$

c. Capacitor Discharge (Current Decay): $\mathrm{I}=\mathrm{Io} * \mathrm{e}-(\mathrm{t} / \mathrm{RC})$

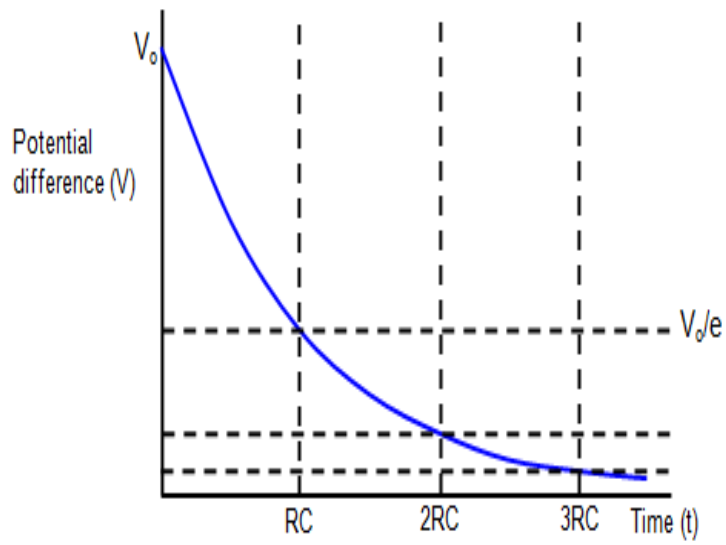

2. For Charging:

a. Capacitor charging (potential difference):

b. $\mathrm{V}=\mathrm{Vo}[1-\mathrm{e}-(\mathrm{t} / \mathrm{RC})]$

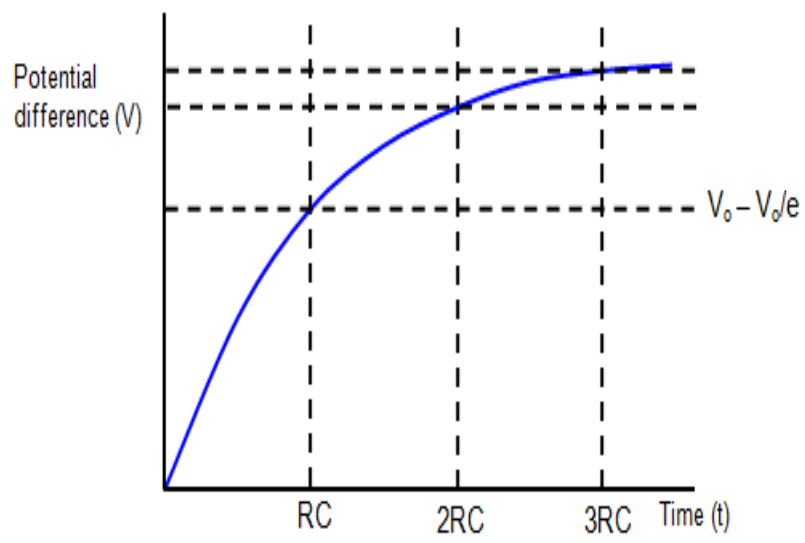

VI. ACTUAL PROJECT
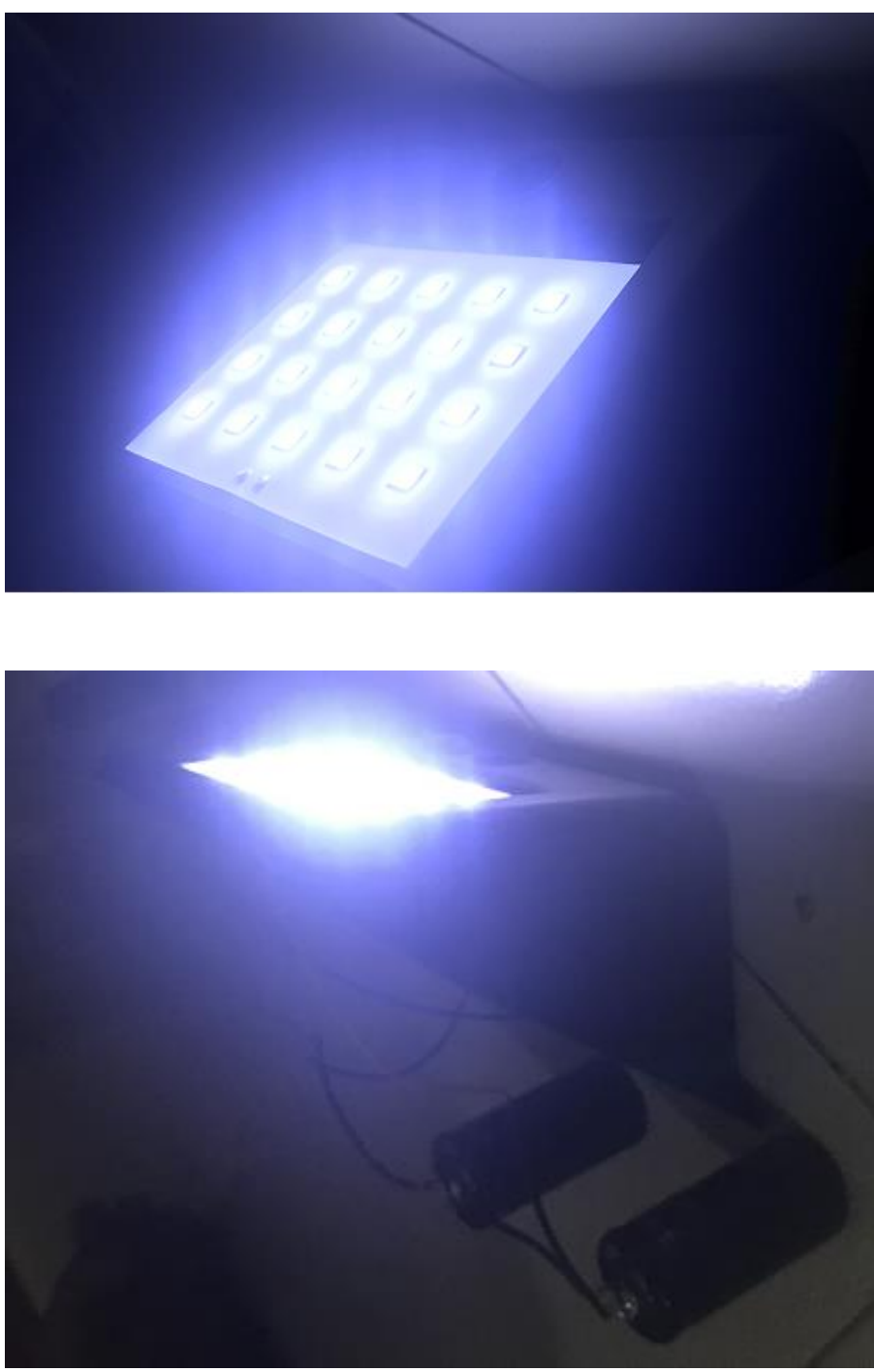


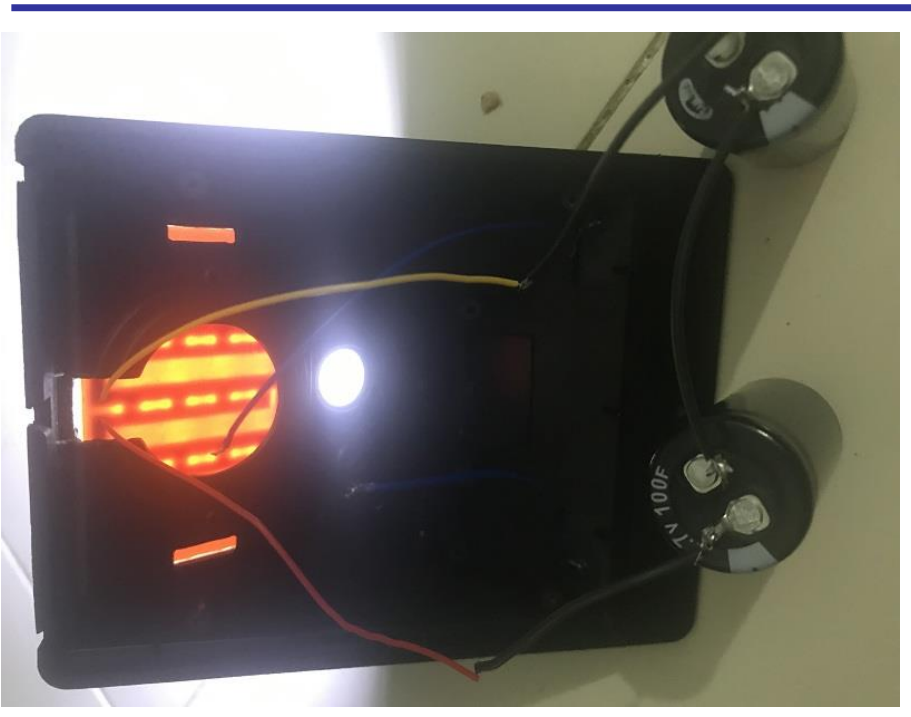

[11] https://historycollection.jsc.nasa.gov/JSCHistoryPortal/history/ro undups/issues/99-05-07.pdf

[12] https://en.wikipedia.org/wiki/Solar_street_light

[13] https://www.researchgate.net/publication/225107113 Comparative study of lead-acid batteries for photovoltaic standalone lighting systems

Article in Journal of Applied Electrochemistry · January 2008 DOI: $10.1007 / \mathrm{s} 10800-007-9403-4$

[14] https://www.researchgate.net/publication/323347741 Design and implementation of smart solar LED street light Conference Paper - May 2017 DOI: 10.1109/ICOEI.2017.8300980

[15] The Analysis of Ultracapacitor Charging Efficiency Conference Paper · Jun 2013 with 28

Reads DOI: 10.1109/ICCIS.2013.317

As can be seen that the SMD LED is operating when connected to UltraCapacitor. Although in current setup it can be seen that the capacitor are connected in series which is not an ideal way to connect capacitor. These UltraCapacitors on later stage were connected in parallel as the capacitance increases in parallel.

\section{CONCLUSION}

We can use UltraCapacitor as a power source replacing the Battery to achieve a feasible Smart Street Lighting System. Although we need more complex controller that can increase the efficiency of the current proposed setup and we can use soft switching for better performance.[]

\section{REFERENCES}

[1] A. Turbary, "Batterie lithium-air : $800 \mathrm{~km}$ d'autonomie pour la voiture électrique en 2020?" site: http://www.voitureelectriquepopulaire.fr/actualites/batterie-lithium-air

[2] A. Vivek Ravi, V. John, "Ultracapacitor Based Ride Through System for Control Power Supplies in High Power Converters" 16th National Power Systems Conference, 15th-17th December, 2010.

[3] B. Hua, C.M. Chunting,G.Sonya "The Short-Time-Scale Transient Processes in High-Voltage and High-Power Isolated Bidirectional DC-DC Converters" IEEE transactions on power electronics, Vol. 23, No. 6, November 2008.

[4] EESL-Street-Lighting-Application-Guide-Final

[5] J. Cao, A. Emadi, "A New Battery/UltraCapacitor Hybrid Energy Storage System for Electric, Hybrid, and Plug-In Hybrid Electric Vehicles" IEEE Transactions on Power Electronics, vol. 27, No. 1, Janury 2012.

[6] M.H. Chabchoub, H. Trabelsi, "DC-DC Converter for UltraCapacitor Boosted Electric Vehicle" IJARET, IAEME, Volume 3, Issue 2, July-December (2012), pp. 71-81.

[7] Nasser Kutkut, "Mosfets vs Igbts: Which is Better?", Technical note, Power Designers. [9] M. Barcaro, N. Bianchi1, "PM Motors for Hybrid Electric Vehicles" The Open Fuels \& Energy Science Journal, 2009, 2, 135-141.

[8] T. Mishima, E. Hiraki, M. Nakaoka "A High Frequency-Link Bidirectional DC-DC Converter for Super Capacitor-Based automotive Auxiliary Electric Power Systems" Journal of Power Electronics, Vol. 10, No. 1, January 2010.

[9] Z. Prof, P. Vaculík "Ultracapacitors Utilization for Automotive Applications" Acta Polytechnica Vol.50 No. 1, 2010.J. Clerk Maxwell, A Treatise on Electricity and Magnetism, 3rd ed., vol. 2. Oxfor: Clarendon, 1892, pp.68-73

[10] https://blogs.nasa.gov/Rocketology/page/3/ 